\title{
Big data simulations for capacity improvement in a general ophthalmology clinic
}

\author{
Christoph Kern ${ }^{1}$ (D) André König ${ }^{1} \cdot$ Dun Jack Fu $^{2} \cdot$ Benedikt Schworm $^{1} \cdot$ Armin Wolf $^{3} \cdot$ Siegfried Priglinger $^{1}$. \\ Karsten U. Kortuem ${ }^{1}$
}

Received: 14 May 2020 / Revised: 7 October 2020 / Accepted: 2 December 2020 / Published online: 2 January 2021

(C) The Author(s) 2020

\begin{abstract}
Purpose Long total waiting times (TWT) experienced by patients during a clinic visit have a significant adverse effect on patient's satisfaction. Our aim was to use big data simulations of a patient scheduling calendar and its effect on TWT in a general ophthalmology clinic. Based on the simulation, we implemented changes to the calendar and verified their effect on TWT in clinical practice.

Design and methods For this retrospective simulation study, we generated a discrete event simulation (DES) model based on clinical timepoints of 4.401 visits to our clinic. All data points were exported from our clinical warehouse for further processing. If not available from the electronic health record, manual time measurements of the process were used. Various patient scheduling models were simulated and evaluated based on their reduction of TWT. The most promising model was implemented into clinical practice in 2017. Results During validation of our simulation model, we achieved a high agreement of mean TWT between the real data $(229 \pm$ $100 \mathrm{~min})$ and the corresponding simulated data $(225 \pm 112 \mathrm{~min})$. This indicates a high quality of the simulation model. Following the simulations, a patient scheduling calendar was introduced, which, compared with the old calendar, provided block intervals and extended time windows for patients. The simulated TWT of this model was $153 \mathrm{~min}$. After implementation in clinical practice, TWT per patient in our general ophthalmology clinic has been reduced from $229 \pm 100$ to $183 \pm 89 \mathrm{~min}$.

Conclusion By implementing a big data simulation model, we have achieved a cost-neutral reduction of the mean TWT by $21 \%$. Big data simulation enables users to evaluate variations to an existing system before implementation into clinical practice. Various models for improving patient flow or reducing capacity loads can be evaluated cost-effectively.
\end{abstract}

Keywords Ophthalmology $\cdot$ Waiting time optimisation $\cdot$ Clinic efficiency $\cdot$ Discrete event simulation $\cdot$ Big data

\section{Key messages}

- Long waiting times in outpatient clinics are known to have a negative impact on patient's satisfaction

- Big data simulations enable users to validate the effect of changes on a target variable (e.g. waiting time) before implementation into clinical practice

- After implementation of our most promising patient scheduling model, we achieved a cost-neutral reduction of patient's waiting time by $21 \%$

Christoph Kern

christoph.kern@med.uni-muenchen.de

1 Department of Ophthalmology, University Hospital LMU Munich, Mathildenstraße 8, 80336 Munich, Germany

2 Moorfields Eye Hospital, London, UK

3 Department of Ophthalmology, Ulm University, Ulm, Germany

\section{Introduction}

Modern healthcare systems struggle to provide high-quality health services for the population because of limited capacity and resources and concomitantly face an increasing number of patients attributable to demographic changes. [1] Budget restrictions emphasise the importance of economic evaluations in the healthcare sector to ensure the efficient and effective use of available resources [2]. Moreover, patient online reviews play an 
increasingly important role in a patient's choice of healthcare provider [3]. Friendliness, empathy, cost, and especially time spent with patients and waiting times are given as being important factors in online reviews [4]. Waiting times have been shown to be a major cause for patient satisfaction in multiple clinical studies [5-8]. The reported correlation between waiting time and patients' satisfaction directly influences the perceived quality of healthcare [9]. Quality management without waiting time optimisation is therefore inconceivable.

The pioneers of patient scheduling optimisation, Welch and Bailey, stated in the early 1950s that the ideal workload of the clinic can be achieved by scheduling patients at fixed intervals [10]. By basing their assumptions on the fact that a doctor's working time is more precious than a patient's time, they were willing to accept long waiting times for patients in clinics. Newer studies suggest that patient scheduling should aim at improving patients' satisfaction by waiting time reduction rather than be based on the ideal occupancy rate of the resource "doctor" [11]. Discrete event simulation (DES) is a method for developing and testing operational solutions over time prior to their implementation in an operating system [12]. This offers a cost-effective solution for imitating and therefore for evaluating the effect of changes on an existing real-world system.

In this study, DES was used to analyse the effect of various patient appointment scheduling models in a general ophthalmology clinic at a tertiary referral centre. Their effect on actual patient flow and their waiting times were examined prior to implementation of the most promising model into clinical practice. Patients' waiting time after implementation is reported as a marker for improved patient flow and resolves capacity strains in clinic.

\section{Methods}

\section{Study setting and design}

This retrospective simulation study performed at the University Eye Hospital of the Ludwig-Maximilian University, Munich, Germany, was designed (i) to create a simulation model on patient flow in our general ophthalmology clinic; (ii) to simulate different patient appointment schedules; and (iii) to implement the best model into clinical practice. Ethical approval for the study was obtained from the Institutional Review Board of the University Eye Hospital Munich in Germany. The study adheres to the Declaration of Helsinki. All data warehouse queries were approved by the local data protection officer.

\section{Study outcomes}

Primary outcome measurement was the reduction in patients' mean "total waiting time" (TWT) after implementation of an advantageous patient scheduling model derived from the simulation analysis. TWT was defined as the time between two timepoints: (i) the patient's registration at the admission desk and (ii) the last editing of the patient's electronic health record (EHR) by an ophthalmologist. Secondary outcome measures were the real state of waiting and process times, the implementation of the DES model and its validation, and the simulation of the effect of the different patient appointment scheduling models on the TWT.

\section{Data source}

Administrative information and timepoints used for further processing were extracted from a data warehouse in use since 2012 [13]. This warehouse contains clinical findings from the patients' EHR; a customized version of i.s.h. med (Cerner AG, Erlangen, Germany) and investigation results for more than 393,000 patients as of February 2020 [14]. Moreover, all digital movements of the patients in the clinic are recorded with a timestamp (start of registration, consultation, and diagnostics). All timepoints are exported as a Microsoft Excel sheet (Microsoft, Richmond, USA) for further processing. Process times that could not be extracted from the database were measured manually, e.g. anterior segment examination or fundoscopy. For the simulation process, digital movements including timestamps for all patients in our general ophthalmology clinic between January and December 2014 were exported as metadata. To measure the effect on TWT after implementation of one of the simulated models, another metadata set was created between October 2016 and June 2017.

\section{Data processing and simulation}

An operational research technique, namely, discrete event simulation (DES), was used to assess the efficacy of the current patient flow and to forecast the effect of modality changes as appointment times or examinations on patient flow without alterations to the present system $[15,16]$. The model was created by using a simulation and modelling software customised for healthcare process analysis (FlexSim Healthcare 3D, Version 5.0.2, FlexSim Software Products Inc., Orem, Utah, USA). The minimal number of replications of the DES model was calculated with Stat::Fit (Geer Mountain Software Corp., South Kent, USA). The following major steps are necessary in the process of conducting a simulation study of any discrete system and are presented in the "Results" part of this manuscript: (i) generation of a simulation model by patient flow analysis, process time measurements, and validation of the model; (ii) experimentation (examination of the effect of modality changes in the patients' appointment schedules on the TWT); and (iii) implementation in clinical practice. [17] 


\section{Statistics}

All clinical data used for this study were queried from the data warehouse as an Excel file and exported to IBM SPSS Statistics for Windows, Version 25.0 (IBM Corp. Armonk, USA), for further statistical analyses. Deviation of metadata and simulated data was assessed by the Kolmogorov-Smirnov test for normality. As data were not normally distributed, paired differences in distribution between meta- and simulated data were analysed by the Mann-Whitney $U$ test to validate our simulation model. Results are presented as mean values including standard deviation (mean $\pm \mathrm{SD}$ ). The level of statistical significance was set at 0.05 . The maximal range of estimates for the DES model was defined as $15 \mathrm{~min}$ at a confidence level of $95 \%$.

\section{Results}

\section{Patient flow analysis}

The first step in DES comprises patient flow analysis. All patients arriving in the hospital are triaged as being an emergency or as having scheduled appointments. For this study, we assessed scheduled patients for the general ophthalmology service. After registration, all patients undergo an anterior segment examination including visual acuity and intraocular pressure measurements by a resident, followed by the application of dilating eye-drops. Depending on medical necessity, an OCT scan is performed prior to binocular fundoscopy. Before leaving the clinic, patients are presented to a consultant for final evaluation (Fig. 1). To improve clarity for the reader, a video of our patient pathway simulation in FlexSim can be found in the supplemental material (supplemental video 1).

\section{Current patients' appointment schedule}

The actual state of the patient scheduling calendar in our clinic consisted of admission times between 7:30 am and 12:50 pm. Until 11:50 am, patients were scheduled in 10min slots. Follow-up and new referrals were randomly mixed. At 12:20, 12:40, and 12:50 pm, three follow-up patients were scheduled for the same slot ("triple" appointment). The 7:30 am appointment was a "double" appointment where the first 2 patients of the day arrived at the same time. Staff included two residents and one consultant. The maximum number of patients scheduled per day and resident was 25 (50 in total).

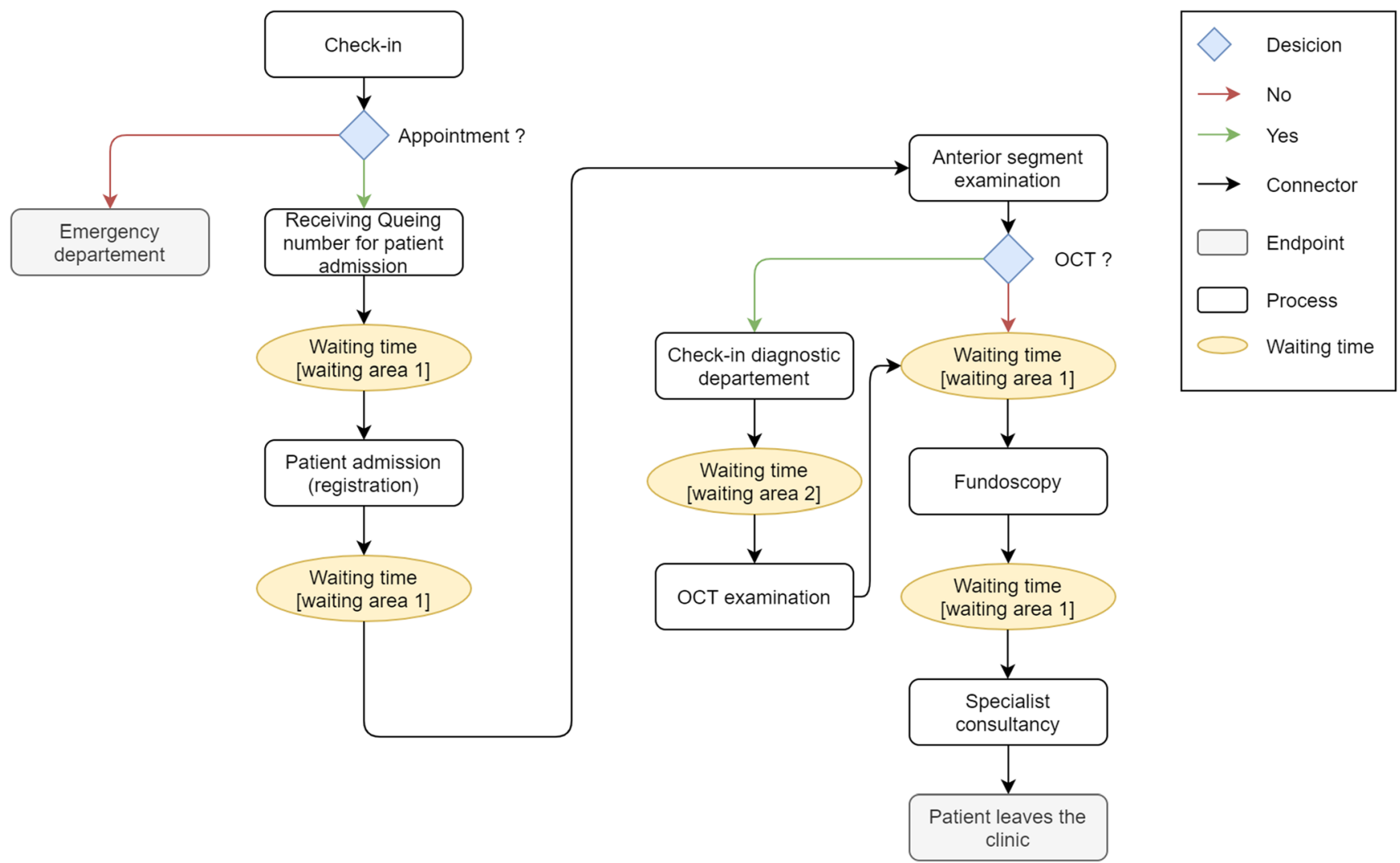

Fig. 1 Patient flow diagram. This represents the pathway including waiting times of scheduled general ophthalmology patients from check-in, through examination ( \pm OCT scan) to consultant presentation before leaving the clinic 
Table 1 Manual measurements of process times in our outpatient clinic

\begin{tabular}{llll}
\hline Process step & $\begin{array}{l}\text { Mean } \pm \text { SD } \\
(\text { minutes })\end{array}$ & $\begin{array}{l}\text { Number of measurements } \\
(n)\end{array}$ & $\begin{array}{l}\text { Distribution of } \\
\text { parameters }\end{array}$ \\
\hline Registration & $3 \pm 1$ & 25 & $\begin{array}{l}\text { Log-Laplace } \\
\text { Johnson bounded }\end{array}$ \\
$\begin{array}{l}\text { Anterior segment } \\
\text { examination }\end{array}$ & $20 \pm 8$ & 23 & Beta \\
New referrals & $24 \pm 7$ & 15 & Weibull \\
Follow-up visits & $12 \pm 3$ & 20 & Beta \\
Binocular fundoscopy & $7 \pm 2$ & 49 & Johnson bounded \\
OCT examination & $4 \pm 1$ & 25 & Johnson bounded \\
Specialist consultancy & $8 \pm 5$ & 23 & \\
\hline
\end{tabular}

\section{Waiting time analysis}

Only digitally available timepoints could be exported on a large scale to generate a simulation model. These were (i) registration at admission; (ii) first contact with the doctor during anterior segment examination; (iii) undergoing optical coherence tomography (OCT) scan; and (iv) end of examination after specialist consultancy. In total, timepoints of 4.401 visits in our general ophthalmology clinic were selected between January and December 2014, of which 33\% (1.452 visits) received an OCT scan and $43 \%$ (1.892 visits) were first referrals. On average, 25 patients per resident attended the clinic during working days. Mean TWT on the day visit was $229 \pm 100 \mathrm{~min}$ for all patients. The following waiting times could be stratified per subgroup: $234 \mathrm{~min}$ for patients undergoing an OCT scan, $237 \mathrm{~min}$ for new referrals, and $223 \mathrm{~min}$ for follow-up visits. On average, patients spent $101 \mathrm{~min}$ in the waiting area before first contact with the doctor. Time between anterior segment examination and receiving an OCT scan was $28 \mathrm{~min}$.

As mentioned above, not all timepoints could be exported from the warehouse. Manual time measurements were performed for the following processes: registration, anterior segment examination, fundoscopy, OCT examination, and specialist consultancy, including their ideal distribution in the DES model (Table 1).

\section{Generating and validating the simulation model}

The DES model was created based on patient flow, metadata previously exported from the data warehouse, and manually measured process times. The definition of the minimal number of replications of a simulation model is necessary to guarantee the precision of the predictions based on the previously defined maximal range of estimates of $15 \mathrm{~min}$ at a confidence level of $95 \%$. The minimal number of replications of our current patient appointment calendar, based on metadata from the warehouse, was 302. Depending on the simulated scenario (current state and Model 1 to 9-see Table 3), between 224 and 399 replications of the model were necessary to reach our maximum range for estimates of $15 \mathrm{~min}$ on a $95 \%$ confidence level. To be on the safe side for all models, we were planning to simulate at a later stage; the minimal number of replications during the experiments was set to 500. To validate the model, it was necessary to compare the distribution of means between not normally
Table 2 Validating simulated data to metadata from the clinical warehouse

\begin{tabular}{lll}
\hline & Metadata & Simulated data \\
\hline Total number of patients (n) & 4.401 & 9.000 \\
TWT (min) & $229 \pm 100$ & $225 \pm 112$ \\
Test for normal deviation * & $\leq 0.01$ & $\leq 0.01$ \\
Distribution of means ** & & 0.72 \\
Patients per day ( $n$ ) & 18 & 18 \\
New referrals & $6(33 \%)$ & $6(33 \%)$ \\
Needing OCT scan & $8(44 \%)$ & $8(44 \%)$ \\
TWT new referrals (min) & $237 \pm 103$ & 227 \\
TWT for OCT scan (min) & $235 \pm 97$ & 247 \\
Waiting time registration to examination (min) & $101 \pm 65$ & 85 \\
Time from examination to OCT scan (min) & $29 \pm 38$ & 23 \\
\hline
\end{tabular}

*Kolmogorov-Smirnov test for normal deviation ( $p \leq 0.05$ implies non-normally deviated data)

**Mann-Whitney $U$ test to compare distribution of means between the groups metadata and simulated data (paired differences test) 
distributed metadata and simulated data by the Mann-Whitney $U$ test. The simulation model was adapted manually until no difference was found between the distribution of means of total waiting time, which implicates comparability between metadata and simulated data $(p$ value $=0.72)$. The simulation model precisely reproduced process times that were generated from the metadata as shown in Table 2. Comparability of means between metadata and our DES model implies a realistic representation of the actual patient flow in our clinic. [18]

\section{Simulation of various patient appointment schedules}

We examined the effects of changes in the patient appointment scheduling calendar on the TWT of patients in the outpatient department by using the previously validated DES model. In addition to the originally validated DES model (no changes = current state), we examined the effect of nine different changes in the patients' admission schedule and staffing on total waiting time (Table 3). Our simulated patients' admission schedules are based on published models, namely, block intervals (model 4) (a certain number of patients arrive at the same time) [19]; fixed intervals (model 5) (varying by number of minutes per slot) [20]; a combination of both with "double" or "triple" appointments at the beginning of each session, followed by fixed intervals (models 2 and 3) [21]. Further alterations to the scheduling calendar, as described in the literature, were simulated: appointments with longest TWT were cancelled and rebooked in fixed intervals at the end of the day (model 1); staffing was increased (models 6, 8, and 9); the order of new referral and follow-ups was changed (model 7) [22, 23].

\section{Implementation into clinical practice}

Model 2 was implemented into clinical practice in 2016. This model resulted in the maximal reduction of total waiting time, without increasing the number of clinic staff. After 9 months of operation, another metadata set was exported in 2017 and compared with the initial state before the performance of big data simulations. This dataset consists of 2.909 visits. Mean total waiting time was reduced from $229 \pm 100 \mathrm{~min}$ before to $183 \pm 89 \mathrm{~min}$ after its implementation in 2017 (Figure 2).
Table 3 Overview of scheduling models including the current state and nine different simulated models

\begin{tabular}{|c|c|c|c|c|c|}
\hline Model & $\begin{array}{l}\text { Slot } \\
\text { per } \\
\text { patient } \\
(\min )\end{array}$ & $\begin{array}{l}\text { Simulated } \\
\text { patients per } \\
\text { resident (n) }\end{array}$ & $\begin{array}{l}\text { Number of } \\
\text { residents and } \\
\text { consultants }(n ; \\
n)\end{array}$ & Changes compared to the current state & $\begin{array}{l}\text { Simulated } \\
\text { TWT } \\
\text { (mean) }\end{array}$ \\
\hline $\begin{array}{c}\text { Current } \\
\text { state }\end{array}$ & 10 & 18 & $2 ; 1$ & $\begin{array}{l}\text { As explained in the "Results" part } \\
\text { "currents patients' appointment } \\
\text { schedule" }\end{array}$ & 225 \\
\hline 1 & 10 & 18 & $2 ; 1$ & $\begin{array}{l}\text { Cancellation of three appointments } \\
\text { with longest TWT. Cancelled } \\
\text { appointments were scheduled after } \\
12: 50 \mathrm{pm} \text { in } 10 \text {-min intervals }\end{array}$ & 178 \\
\hline 2 & 20 & 19 & $2 ; 1$ & $\begin{array}{l}\text { "Triple" appointments at 7:30 and } \\
\text { 10:00 am. Fixed 20-min intervals } \\
\text { from } 8 \text { am to } 2 \mathrm{pm}\end{array}$ & 153 \\
\hline 3 & 15 & 18 & $2 ; 1$ & $\begin{array}{l}\text { "Triple" appointments at 8:00 am; } \\
\text { "double appointments" at } 10 \text { am and } \\
1 \mathrm{pm} \text {, fixed } 15 \text {-min intervals from } 8 \\
\text { am to } 2 \mathrm{pm}\end{array}$ & 181 \\
\hline 4 & 15 & 18 & $2 ; 1$ & $\begin{array}{l}\text { Fixed block intervals: four patients } \\
\text { every hour at the same time from } 8 \\
\text { am to } 2 \text { pm }\end{array}$ & 164 \\
\hline 5 & 10 & 18 & $2 ; 1$ & $\begin{array}{l}\text { Model } 1 \text { without the } 7: 30 \mathrm{am} \text { "double" } \\
\text { appointment. Fixed 10-min intervals } \\
\text { from 7:30 am to } 12: 50 \mathrm{pm}\end{array}$ & 169 \\
\hline 6 & 10 & 22 & $3 ; 1$ & Current state with 1 additional resident & 214 \\
\hline 7 & 10 & 17 & $2 ; 1$ & $\begin{array}{l}\text { Current state but new patients were } \\
\text { scheduled prior to follow-up pa- } \\
\text { tients. }\end{array}$ & 238 \\
\hline 8 & 10 & 23 & $3 ; 2$ & $\begin{array}{l}\text { Current state with } 1 \text { additional resident } \\
\text { and consultant (increased staffing) }\end{array}$ & 216 \\
\hline 9 & 10 & 22 & $3 ; 1$ & $\begin{array}{l}\text { Model } 2 \text { with } 1 \text { additional resident } \\
\text { (increased staffing) }\end{array}$ & 125 \\
\hline
\end{tabular}


Fig. 2 Histogram analysis of TWT before and after implementation of model 2. Intervals on $\mathrm{x}$-axis are set to 20 $\min$
Total waiting time ( $\mathrm{min})$ - before improvement
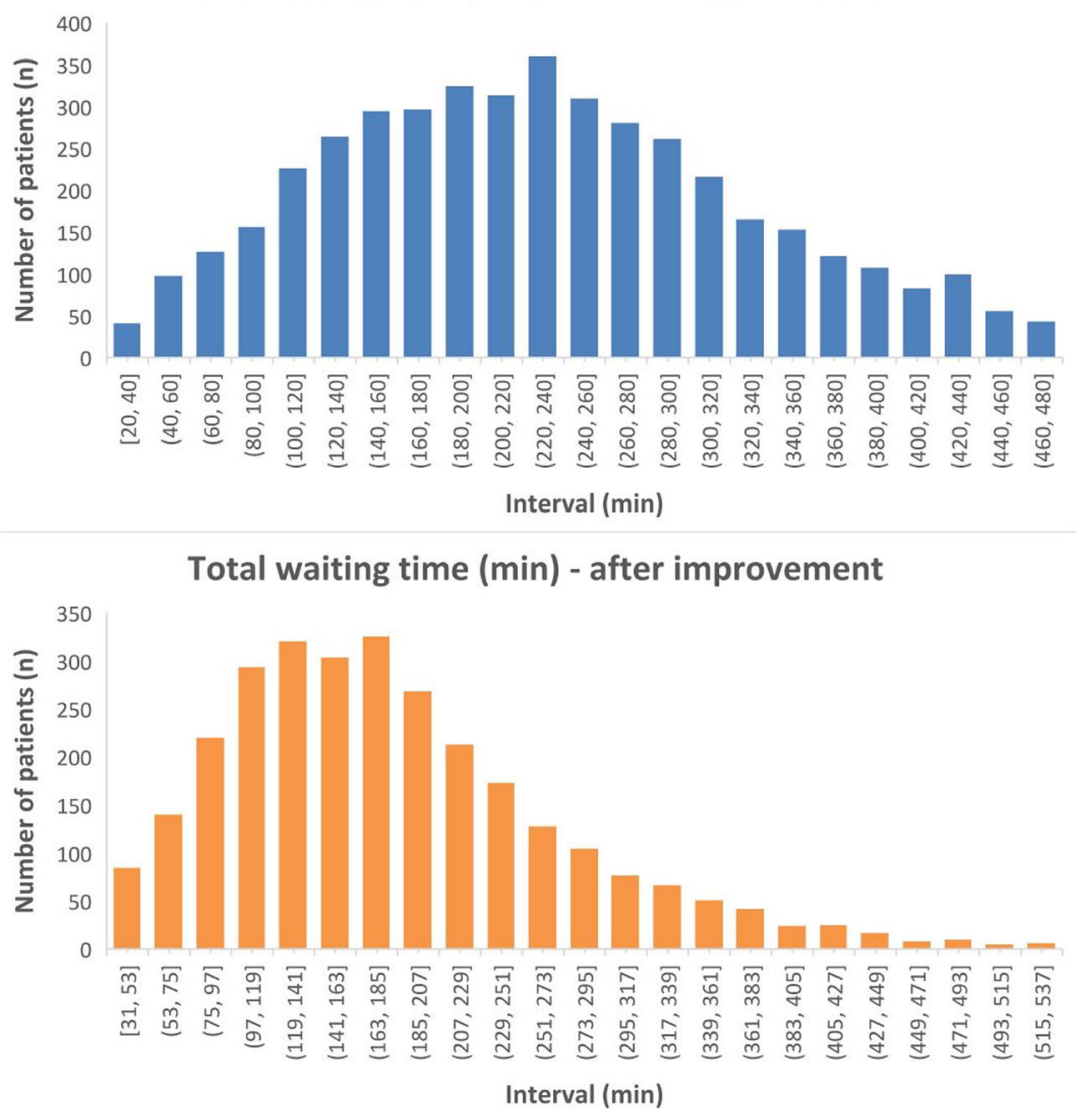

\section{Discussion}

\section{Main findings}

Total waiting time of patients in our general ophthalmology outpatient department has been reduced by $21 \%$ from $229 \pm$ 100 to $183 \pm 89 \mathrm{~min}$. This was achieved by big data simulations based on a discrete event simulation model. Various changes in patient scheduling were compared easily and cost-effectively by their effect on waiting times in clinical practice. This reduction in waiting time was achieved without the hiring of new staff or the acquisition of new machines or reconstruction work and resulted in a capacity improvement in our clinic.

\section{Findings in the light of the current literature}

To our knowledge, this is the first study to use data derived from a clinical data warehouse for process and waiting time optimisation. In countries with highly developed healthcare systems, approximately $80 \%$ of small and general hospitals employ EHR [24]. As of 2019, only one-third of them truly work in a paperless fashion leaving a huge gap for further digitalisation. This progress will make data, stored in corresponding data warehouses, more and more accessible and will allow the application of comparable big data simulations as presented in this study on a broader scale, thereby affecting quality management and relieving capacity strains in healthcare [25].

DES models have previously been used for improving patient appointment scheduling. Waiting time of patients has been reduced by the wider distribution of appointment slots and the rearrangement of new and follow-up slots [18]. These results correspond to ours: increasing the slot time per patient from 10 (current state) to 15 (model 4) and $20 \mathrm{~min}$ (model 2) results in a simulated reduction of TWT from $229 \mathrm{~min}$ to 164 and $153 \mathrm{~min}$, respectively. On the contrary, they reach process optimisation by reserving afternoon slots exclusively for follow-up patients with similar pathways. In our DES model, this approach even increased TWT as compared with the initial state from 229 to $238 \mathrm{~min}$. This discrepancy might be explained by the training grade of staff in our general ophthalmology clinic, namely, "year one" residents without knowledge of common pathways for follow-up patients.

Another approach focused on the reduction of patient visit times and originates from industrial manufacture: the Lean Six Sigma technique maximises positive results, namely, the reduction of patient waiting time [26]. After implementing the most promising model into clinical practice at a vitreoretinal outpatient clinic, patient visit times were reduced by $18 \%$. Our model achieved a comparable reduction of TWT of $21 \%$.

Multiple studies have shown that up to $80 \%$ of patients arrive prior to their actual appointment [27, 28]. In addition 
to patient appointment schedule optimisation, appointment discipline might improve waiting times in clinics. Low appointment discipline results not only in waiting area congestion but also in a suboptimal use of available resources because of the irregular arrival of patients [29].

\section{Strengths and limitations}

The major advantage of DES models is that changes in patient scheduling can be implemented easily and cost-effectively into clinical practice without the hiring of new staff or the acquisition of new machines or reconstruction work [12]. Moreover, DES allows the reduction of patient waiting time, resource overtime, and waiting area congestion by the simulation and optimisation of the use of available resources. [29]

On the other hand, the accuracy of our DES model might be compromised by the following circumstance. Only timestamps from the EHR and manual process time measurements could be used for generating the model. The first timestamp available is the first contact with our administration office. The initial waiting time of the patient after receiving the queuing number is therefore not represented in the model (Fig. 1). Two reasons are responsible for this fact: (i) the queuing number machine is not connected to the data warehouse or the EHR; (ii) patients with appointments in our general ophthalmology clinic cannot be identified upon arrival in the clinic prior to their check-in at the admission desk. Measurement of the initial waiting time was therefore not possible.

\section{Implications for further research}

As discussed previously, waiting time (negative correlation) and consultation time (positive correlation) are correlated with patient satisfaction. This correlation is significantly stronger in the first $90 \mathrm{~min}$ of the waiting time and in the first $15 \mathrm{~min}$ of the consultation time [30]. On the other hand, a waiting time of up to $45 \mathrm{~min}$ has no impact on patient satisfaction and seems to be acceptable [8]. Manual process measurements in this study have shown that patients spent in total 39 min with a doctor during their visit (including anterior segment and fundus examination, OCT, and specialist consultancy). This leaves $146 \mathrm{~min}$ of real waiting time resulting in a strong negative impact on patient satisfaction. Future studies should include patient satisfaction in big data simulation models.

\section{Implication for clinical practice}

We believe that DES simulations, as presented in this study, might be applicable in other settings such as at private ophthalmologist or other healthcare systems. The private sector is facing an increasing number of patients and waiting times, whilst competing for valuable patients. Because waiting time has a direct correlation on patient satisfaction and therefore recommendation rates, DES might be an economically valuable tool outside larger ophthalmic referral centres $[3,4,25]$. In the light of digitalization of healthcare and therefore the broader availability of metadata, this method can be used to optimize patient flow and therefore waiting time without producing additional costs. By its cost-effectiveness and adaptability to other settings, this method is qualified for implementation in other healthcare systems with limited resources as well.

\section{Conclusion}

Big data simulations offer the opportunity to simulate patient appointment scheduling cost-effectively and efficiently but without introducing alterations to an existing system. After implementation of the most promising simulation model, patients' total waiting time in our outpatient clinic could be reduced by 46 min $(-21 \%)$. Simulation models might thus improve patient flow and capacity strains in other ophthalmologic services.

Supplementary Information The online version contains supplementary material available at https://doi.org/10.1007/s00417-020-05040-9.

Funding Open Access funding enabled and organized by Projekt DEAL. Christoph Kern reports grants and personal fees from Bayer AG, grants from Carl Zeiss Meditech, outside the submitted work.

André König has nothing to declare.

Dun Jack Fu has nothing to declare.

Benedikt Schworm received speaker fees from Novartis, outside the submitted work.

Siegfried Priglinger has nothing to declare.

Armin Wolf has nothing to declare.

Karsten Kortuem reports grants and personal fees from Novartis Pharma, grants and personal fees from Bayer Pharma, personal fees from Zeiss, personal fees from Big Picture Healthcare, personal fees from Google Deepmind, personal fees from Allergan, outside the submitted work.

\section{Compliance with ethical standards}

Conflict of interest The authors declare that they have no conflict of interest.

Ethical approval All procedures performed in studies involving human participants were in accordance with the ethical standards of the University Hospital Munich, LMU, Germany, and with the 1964 Helsinki declaration and its later amendments or comparable ethical standards. Ethical approval was obtained by the university's ethics committee under the approval number 17-875.

Informed consent For retrospective research was obtained from all individual participants included in the study.

Open Access This article is licensed under a Creative Commons Attribution 4.0 International License, which permits use, sharing, adaptation, distribution and reproduction in any medium or format, as long as you give appropriate credit to the original author(s) and the source, provide a link to the Creative Commons licence, and indicate if 
changes were made. The images or other third party material in this article are included in the article's Creative Commons licence, unless indicated otherwise in a credit line to the material. If material is not included in the article's Creative Commons licence and your intended use is not permitted by statutory regulation or exceeds the permitted use, you will need to obtain permission directly from the copyright holder. To view a copy of this licence, visit http://creativecommons.org/licenses/by/4.0/.

\section{References}

1. Lopreite M, Mauro M (2017) The effects of population ageing on health care expenditure: a Bayesian VAR analysis using data from Italy. Health Policy 121(6):663-674. https://doi.org/10.1016/j. healthpol.2017.03.015

2. Mills M, Kanavos P (2020) Do pharmaceutical budgets deliver financial sustainability in healthcare? Evidence from Europe. Health Policy 124(3):239-251. https://doi.org/10.1016/j.healthpol. 2019.12.002

3. Hong YA, Liang C, Radcliff TA, Wigfall LT, Street RL (2019) What do patients say about doctors online? A systematic review of studies on patient online reviews. J Med Internet Res 21(4): e12521. https://doi.org/10.2196/12521

4. Bakhsh W, Mesfin A (2014) Online ratings of orthopedic surgeons: analysis of 2185 reviews. Am J Orthop (Belle Mead NJ) 43(8):359363

5. Mazaheri Habibi MR, Abadi FM, Tabesh H, Vakili-Arki H, AbuHanna A, Eslami S (2018) Evaluation of patient satisfaction of the status of appointment scheduling systems in outpatient clinics: identifying patients' needs. J Adv Pharm Technol Res 9(2):5155. https://doi.org/10.4103/japtr.JAPTR_134_18

6. Xie Z, Or C (2017) Associations between waiting times, service times, and patient satisfaction in an endocrinology outpatient department: a time study and questionnaire survey. INQUIRY: The Journal of Health Care Organization, Provision, and Financing 54: 0046958017739527

7. Lee S, Groß SE, Pfaff H, Dresen A (2020) Waiting time, communication quality, and patient satisfaction: an analysis of moderating influences on the relationship between perceived waiting time and the satisfaction of breast cancer patients during their inpatient stay. Patient Educ Couns 103(4): 819-825

8. Nottingham QJ, Johnson DM, Russell RS (2018) The effect of waiting time on patient perceptions of care quality. Qual Manag J 25(1):32-45

9. Abidova A, da Silva PA, Moreira S (2020) Predictors of patient satisfaction and the perceived quality of healthcare in an emergency department in Portugal. West J Emerg Med 21(2):391-403. https:// doi.org/10.5811/westjem.2019.9.44667

10. Welch JD, Bailey NT (1952) Appointment systems in hospital outpatient departments. Lancet 1(6718):1105-1108. https://doi.org/10. 1016/s0140-6736(52)90763-0

11. Lowes R (2008) Smarter scheduling puts you in control. Med Econ 85(2):50-52, 54, 56-57

12. Hamrock E, Paige K, Parks J, Scheulen J, Levin S (2013) Discrete event simulation for healthcare organizations: a tool for decision making. J Healthc Manag 58(2):110-124 discussion 124-115

13. Kortum K, Kern C, Meyer G, Priglinger S, Hirneiss C (2017) Required framework for the collection of real-life data: an example from University Eye Hospital Munich. Klin Monatsbl Augenheilkd 234(12):1477-1482. https://doi.org/10.1055/s-0043-115900
14. Kortum K, Muller M, Hirneiss C, Babenko A, Nasseh D, Kern C, Kampik A, Priglinger S, Kreutzer TC (2016) Smart eye data : development of a foundation for medical research using Smart Data applications. Ophthalmologe 113(6):469-477. https://doi.org/10. 1007/s00347-016-0272-2

15. Eiselt HA, Sandblom C-L (2012) Operations research: A modelbased approach. Springer Science \& Business Media

16. Jun JB, Jacobson SH, Swisher JR (1999) Application of discreteevent simulation in health care clinics: a survey. J Oper Res Soc 50(2):109-123. https://doi.org/10.1057/palgrave.jors.2600669

17. Shannon RE (1998) Introduction to the art and science of simulation. In: 1998 Winter Simulation Conference. Proceedings (Cat. No. 98CH36274). IEEE, pp 7-14

18. Pan C, Zhang D, Kon AW, Wai CS, Ang WB (2015) Patient flow improvement for an ophthalmic specialist outpatient clinic with aid of discrete event simulation and design of experiment. Health Care Manag Sci 18(2):137-155. https://doi.org/10.1007/s10729-0149291-1

19. Cayirli T, Veral E (2003) Outpatient scheduling in health care: a review of literature. Prod Oper Manag 12(4):519-549

20. Klassen KJ, Rohleder TR (1996) Scheduling outpatient appointments in a dynamic environment. J Oper Manag 14(2):83-101

21. Cayirli T, Veral E, Rosen H (2006) Designing appointment scheduling systems for ambulatory care services. Health Care Manag Sci 9(1):47-58

22. Harper PR, Gamlin HM (2003) Reduced outpatient waiting times with improved appointment scheduling: a simulation modelling approach. OR Spectr 25(2):207-222. https://doi.org/10.1007/ s00291-003-0122-x

23. Zhu Z, Heng BH, Teow KL (2012) Analysis of factors causing long patient waiting time and clinic overtime in outpatient clinics. J Med Syst 36(2):707-713. https://doi.org/10.1007/s10916-010-9538-4

24. Park YT, Kim YS, Yi BK, Kim SM (2019) Clinical decision support functions and digitalization of clinical documents of electronic medical record systems. Healthc Inform Res 25(2):115-123. https://doi.org/10.4258/hir.2019.25.2.115

25. Tan SS, Gao G, Koch S (2015) Big data and analytics in healthcare. Methods Inf Med 54(6):546-547. https://doi.org/10.3414/me1506-1001

26. Ciulla TA, Tatikonda MV, ElMaraghi YA, Hussain RM, Hill AL, Clary JM, Hattab E (2018) Lean Six Sigma techniques to improve ophthalmology clinic efficiency. Retina 38(9):1688-1698. https:// doi.org/10.1097/IAE.0000000000001761

27. Fetter RB, Thompson JD (1966) Patients' waiting time and doctors' idle time in the outpatient setting. Health Serv Res 1(1):66-90

28. Lehaney B, Clarke SA, Paul RJ (1999) A case of an intervention in an outpatients department. J Oper Res Soc 50(9):877-891. https:// doi.org/10.1057/palgrave.jors.2600796

29. Lin CKY, Ling TWC, Yeung WK (2017) Resource allocation and outpatient appointment scheduling using simulation optimization. J Healthc Eng 2017:9034737. https://doi.org/10.1155/2017/9034737

30. Alarcon-Ruiz CA, Heredia P, Taype-Rondan A (2019) Association of waiting and consultation time with patient satisfaction: secondary-data analysis of a national survey in Peruvian ambulatory care facilities. BMC Health Serv Res 19(1):439. https://doi.org/ 10.1186/s12913-019-4288-6

Publisher's note Springer Nature remains neutral with regard to jurisdictional claims in published maps and institutional affiliations. 